\title{
HR activities and practices for project success: A multi- method approach from Indian IT firms
}

\section{Vanita Bhoola}

S. P. Jain Institute of Management and Research

India

vanita@spjimr.org

\section{Antonio Giangreco}

IESEG School of Management, Lille

France

\section{Abstract}

The purpose of this study is to examine the impact of Human Resource activities and practices (HRAPs) on value-driven project management in the Indian IT industry. It is a sector that offers various jobs for young IT skilled labour force, but faces major challenges in recruiting and retaining talent. A multi-method research has been carried out, using Delphi technique and a simultaneous equations model. Using the Delphi method, we developed an initial set of 136 globally accepted HRAPs. This was reduced to 20 most significant attributes applicable to Indian IT projects with the help of Kendall's coefficient of concordance (W) used over three rounds of iterations. Later, from 431 observations, we selected the top 10 HRAPs based on mean ranks in round 3 to study the impact on value-driven project success, in terms of meeting project, customer and organizational goals. The study also uses triangulation through a multimethod research approach to achieve convergence. The significant HRAPs impacting valuedriven project management include efficient project leadership, effective communication, training of project leaders, ensuring job-matching and listening to team members' issues. Frequent team conflicts and personnel turnover, however, adversely impact IT project success. Our results confirm that the impact of HRAPs on project goals is more prominent and immediate as compared to meeting customer or organizational goals, which is often delayed. The results emphasize the necessity of integrating all stakeholders of IT projects in order to accomplish value-driven success.

Keywords: value-driven project success, multi-method research, Delphi method, Full Information Maximum Likelihood Estimation, Human Resources Management Activities and Practices.

\section{Introduction}

Sourcing low cost resources to cut operating expenses has enabled information technology (IT) activities and projects to be executed from destinations like India, Brazil, the Philippines, etc. where the workforce is young and intellectual capital is abundant (Viji, 2016). The Indian IT industry is poised to become a global powerhouse as its services sector is projected to grow to USD 154 billion, with presence in over 52 countries, 500 global delivery centres, and 600,000 foreign nationals (NASSCOM, 2017). Indian IT multinationals recruit a workforce of 10 million and account for $67 \%$ of the US market, with an overwhelming global reputation (Majumdar, 2013; Thite et al., 2014).

Information Technology is a typical industry where activities are developed according to the logic of projects and client satisfaction is considered as the uppermost indicator of project 
success (Diegmann et al., 2017). Despite the needs for different success criteria of customer satisfaction and organization goals, project success is mostly measured in terms of time and scope completion, and meeting costs (Basten et al., 2014). Consider the case of e-governance projects in India - apart from barriers like awareness, literacy rates, or security issues, to implementation at the grassroots level, such projects face HR challenges in aligning resources to meet business goals (Prakash, 2016). Hence, achieving success of IT projects is complex.

Originating with Rockart (1979), several studies have discussed the critical success factors relevant to IT projects (Blaskovics, 2016; Esteves, 2014; Keil et al., 2013; Remus and Wiener, 2010). Based on a database of over 50,000 IT firms built up between 2007 and 2016, Standish Group's Chaos Report Outline (2016) observes that less than 29\% of these projects are successful. Similarly, a recent investigation from the cloud provider Innotas shows that 55\% of the 126 IT professionals surveyed between January and March 2015 reported project failures due to mismatched resource allocation and alignment with business goals (Florentine, 2016). While reasons for project failure could be many (Hughes et al., 2017), human resource management (HRM) emerges as a significant reason (Jean-Sébastien, 2016). Zidane and Bjorn (2018) document poor HRM has the fourth most important "universal delay factors" in project execution. The role of HRM to determine project success is well-researched, although mostly originated from the United States or Europe (Farndale et al., 2010; Korsakienè et al., 2015). While this provides a rationale to consider India as a case in point, changing business environment, potential threats of labour turnover and practice of Western-centric HR principles are increasing the risks of IT project failure even further (Thite et al., 2014). A specific focus to such studies that discuss the non-Western world is rare (Bhoola, 2015) and more research is welcome in this area (Budhwar et al., 2016). A gap therefore exists in the literature.

This research aims at filling this gap by identifying the HR activities and practices (HRAPs) that might affect the success of projects in the IT industry, with a view later to formulating requirements for policies that might be particularly relevant for practitioners as HRAPs designed for IT projects should be standardized as they need great attention in a project-based organization (Keegan et al., 2012; Huemann, 2010). This is done by detecting and testing a panel of HRAP related measurement items that might affect the success of a project in the Indian IT industry, based on a dataset coming from a survey of 431 observations, collected during 2014-15, from 18 organizations that have provided project management training to their employees. In doing that, instead of limiting the definition of project success to the quadruple constraints of meeting cost, time, scope and quality, we consider value-driven project management that provides a holistic view to project success by aligning project goals with organization and customer goals (Shenhar et al., 2001). Value-driven project management is effective only if it is co-created along with people; else it will remain a vision, seldom achieved (Bhoola, 2016). Using the Delphi method, we narrowed down on a set of HRAPs and used this to evaluate their impact on value-driven project management.

The rest of the article is structured as follows. The following section provides a background of literature on IT projects particularly in the Indian context. We continue by presenting the research methodology and its rationale. In the following section, we elaborate on the findings from the Delphi method, and then of the Full Information Maximum Likelihood Estimation (FIMLE) method. We conclude by discussing the triangulation of the qualitative and quantitative methods, the theoretical contribution and managerial implications of the study. 


\section{HR practices, IT industry and India}

India has 179 languages and 154 dialects, with an uneven distribution of literacy rate (Rao, 2015). Though rich in culture and natural resources, India continues to face multiplicity of problems including, political and religious instability; increasing population, unemployment and poverty; relatively low per-capita income; unmanageable public sector companies and bureaucracy; and inequality in income distribution (Budhwar, and Debrah, 2013). Regional differences, caste systems, socioeconomic status, and urban-rural divide add to the misery (Rao, 2015).

Globalization and liberalisation policies have enforced competition, fostering more creativity and innovation among Indian organizations (Som, 2006). In order to manage its workforce, India mostly follows global best practices to implement HRM systems (Bjorkman and Lu, 2001). There is a growing theoretical appreciation that HR practices are contextual and culture specific (Bossard and Peterson, 2005; McMahan, Bell and Virick, 1998; Bowen, Galang, \& Pillai, 2002; Budhwar and Bhatnagar, 2008; Budhwar and Khatri, 2001). Given the socioeconomic and cultural diversity of India, imitating global practices could be mired with challenges. Researchers have typically discussed Western-focused cross-country and cross-cultural HR applications and practices. However, there is serious dearth of such studies based on Indian HR perspectives (Triandis, 1989; von Glinow et al., 2002).

With a growth reaching USD 1 trillion, the IT industry in India is among the top job creators worldwide, with two-third of its operations and exports from North America, Western Europe, and Asia Pacific (Patel and Budhwar, 2010). With a whopping 55 percent share of global market, the Indian IT services sector provides direct employment to 2.8 million people in India; moreover, with its presence in 52 countries with over 500 global delivery centres it employs over 600,000 foreign nationals (Rao and Balasubrahmanya, 2017). Recruiting, retaining, and developing human intellectual talent with a global mindset is one of the key success factors for Indian offshore service providers (Chadee, Raman, and Michailova, 2011), as global HR management capabilities play a key role in effectively leveraging the intangible resources for successful performance of these firms (Lahiri, Kedia, and Mukherjee, 2012).

Multinational companies usually try to keep the balance between parent and subsidiary globally by also using standardized HR practices, (Mathew, Jain and Bedi, 2012). In coping with the challenges coming from operating at the worldwide level, multinational Indian organizations instead have been more reactive than proactive in its approaches to HRM. Ignoring the HR function over decades has therefore built up pressure on the industry (Thite, Wilkinson Budhwar and Mathews, 2016).

Given the nature of the industry, the type of intellectual workforce and the high economic growth rate are leading to scarcity of manpower (Yadav and Yadav, 2017), so that the right approach to HR applications and practices becomes a key challenge for the resent and the future. It is indeed a tightrope walk to ensure the right balance of leadership, communication, motivation and also managing conflicts and turnover in order to lead to project success on one hand, and gaining the confidence of team members, customers and organization, on the other (Todorović et al., 2015). Hence, considering the present dynamic business environment, it is crucial for Indian organizations the need to pursue more proactive HRM practices, by customizing it with Indian traditional values, religious and ethnic backgrounds and introducing innovative culture-building practices (Som, 2006); Rao and Balasubrahmanya, 2017). Clearly, this calls for a transition of HR from traditional roles to roles that integrate all 
stakeholders who are directly or indirectly associated with the project, in order to achieve value-driven success (Stulgienè and Čiutienė, 2012).

\section{Previous studies}

While there are different factors that lead to successful project implementation, HR management and facilitating a collaborative work environment is of high relevance for IT companies (Ravid et al., 2012). IT projects are characterized by speed, relevance, changing requirements, interdependency, complexity, uniqueness and ambiguity (Bathallath, Smedberg and Kjellin, 2017). Hence, lack of clarity in human responsibilities across various phases of project life cycle adversely impacts IT project success (Keegan, et al., 2012; Hoda and Murugesan, 2016).

While HR practices are strategic in nature and provide a guiding force to the project organization, HR activities provide the implementation of the directives set through HR practices (Koulikoff-Souviron and Harrison, 2010). HR activities and practices (HRAPs) include the strategic HR directions of the project organization that ensure recruitment and selection, personnel planning, training and development, performance management, teamwork, performance related pay, employment security, internal career possibilities, participation, communication, job design, job description, work-life balance and various other activities (van de Voorde et al., 2012). In project-oriented companies, effective management of HRAPs like employee performance and development, turnover, team communication, experience learning, job-matching, etc. not only influence the project manager, but also the project and the organization (Keegan, Huemann and Turner, 2012). Unless HRAPs lead to cohesive team-building, healthy communication and transformational leadership, project success would remain a myth (Aga, Noorderhaven and Vallejo, 2016). Indeed, replacing the top-down approach with a more flexible mechanism, especially in the case of project resource allocation, by drawing experiences from the grass-root level of the organization is of critical importance (Momeni and Martinsuo, 2018).

Researchers have extensively studied the role of HR in affecting organisational performances (Foss et al., 2015; Van Dierendonck et al., 2016). Belout and Gauvreau (2004) show that the role of HR in project management is changing beyond the "Personnel factor" (Pinto and Prescott, 1988) and the traditional HRM (Van Marrewijk and Timmers, 2003). Project success depends much on management support, project manager's role and allied support factors that make the role, responsibility and operation of the HR, effective (Turner and Müller, 2005). Batistič and Kenda (2018) talk about organizational socialization to enhance productivity. They provide a framework to describe how new members of a project should socialized effectively to ensure smooth inclusion and better contribution to the projects.

In the Indian context, the IT industry is playing a leading role in designing innovative solutions to face unique and enterprising challenges by incorporating social, mobile, analytics and cloud technologies (Sahoo and Nauriyal, 2014). Unlike infrastructure construction projects, IT projects generally span multiple geographical locations, involving people from diversified cultures and backgrounds, using multiple work standards and technologies (Lee and Baby, 2013). Hence, the presence of project team cohesion, employee-friendly working environment, supportive leadership, collaborative management and favourable HRAPs can influence the quality of deliverables and value-creation (Khan and Rasheed, 2015). HRAPs in IT projects are mainly the domain of project managers, rather than the HR department or other 
line managers. This requires healthy interchange of communication between the HR department and project managers (Keegan et al., 2012). Hence, our focus on HRAPs is from the perspectives of project managers.

We argue that though there are various factors that lead to successful IT project implementation, effectively managing HRAPs is the key element to avoid IT project failures (Hughes et al., 2017). In project-oriented companies, HRAPs not only influence the line manager or the project manager, but also the organization at a larger level in the long run (Keegan et al., 2012).

While the role of HRAPs in IT project success is widely researched, there is a dearth of such studies from the Indian perspective (Thomas and Bhasi, 2012) that capture their ranking (Cuellar, 2010). Earlier studies dedicated to identifying HRAPs that influence IT project performance and success, are mainly from the perspective of the Western world (Bhoola, 2015). There is dearth of literature that addresses the role of HRAP in IT projects considering India or Southeast Asia. Also, previous research either focuses on a qualitative methodology based on Delphi study (Keil et al., 2013), in-depth interviews (Thite et al., 2014) or compilation of case studies (Keegan et al., 2012) or depends on a quantitative model (Khan and Rasheed, 2015) to determine the HRAP factors. Studies that use a multi-method research approach (Remus and Wiener, 2008) are rare. This study bridges the gap by initially starting with 136 globally accepted HRAPs that influence project success, then gradually narrowing down to just ten customized factors using Delphi method, that are applicable to the Indian context. The study uses triangulation (Morse, 2003) to ensure convergence of findings. Specifically, we posit to address the following research questions:

RQ1: What are the HRAPs, in order of importance, that influence IT project success, in the Indian context?

RQ2: Are there HRAPs that are specific to the Indian context, as compared to the global experience?

RQ3: How do the most important HRAPs influence value-driven project success?

RQ4: Is it possible to develop a comprehensive picture that can triangulate the findings from multimethod strategies?

\section{Research methodology}

We wish to address RQ1 by using the Delphi method. The inputs from RQ1 can be used to draw a comparative analysis of the findings and literature to answer RQ2. Drawing on the major findings from RQ1, we will derive a smaller set of HRAPs. In order to address RQ3 we will use a simultaneous equations model. The purpose of RQ4 is to logically integrate the findings of RQ1 and RQ3 and check for triangulation. 


\begin{tabular}{cclllc}
\hline $\begin{array}{c}\text { Respond- } \\
\text { ent }\end{array}$ & Age & \multicolumn{1}{c}{ Education } & Gender & \multicolumn{1}{c}{ Designation } & $\begin{array}{c}\text { Number of } \\
\text { projects managed }\end{array}$ \\
\hline 1 & 36 & Graduate & Male & Development Team Member & 10 \\
2 & 44 & Post Graduate & Female & Project Leader & 29 \\
3 & 40 & Graduate & Male & Team Leader & 20 \\
4 & 44 & PMP & Male & Quality Manager & 30 \\
5 & 38 & PMP & Male & Development Team Member & 14 \\
6 & 42 & PRINCE & Male & Project Leader & 26 \\
7 & 36 & Certification in PM & Male & Systems Analyst & 10 \\
8 & 42 & Graduate & Male & Team Leader & 27 \\
9 & 36 & Certification in PM & Male & Project Leader & 10 \\
10 & 37 & Graduate & Male & Development Team Member & 12 \\
11 & 39 & Post Graduate & Male & Project Manager & 18 \\
12 & 42 & PRINCE & Male & Project Leader & 27 \\
13 & 41 & Graduate & Male & Project Manager & 21 \\
14 & 38 & PMP & Female & Quality Manager & 15 \\
15 & 41 & Graduate & Male & Project Leader & 26 \\
16 & 43 & Graduate & Male & Project Manager & 28 \\
17 & 44 & Post Graduate & Male & Project Leader & 32 \\
18 & 37 & Graduate & Male & Project Manager & 13 \\
19 & 38 & PMP & Male & Project Manager & 16 \\
20 & 38 & Graduate & Female & Development Team Member & 17 \\
21 & 41 & Graduate & Male & Project Leader & 23 \\
\hline
\end{tabular}

Table 1: Profile of respondents of the Delphi Method

Keil et al. define the Delphi method as "a group decision-making process where, through iterative feedback, the opinions of a panel of experts are elicited and consensus is reached" (2013, p.400). As the purpose of RQ1 is to unearth the relevant aspects of HRAPs used in Indian IT project management and determine the relative importance of issues, we used the Delphi method with three distinct phases namely, discovering, determining and ranking (Keil et al., 2013; Schmidt, 1997; Schmidt et al., 2001). A convenient sample of 21 respondents was selected from the Mumbai and Bangalore chapters of Project Management Institute (PMI), from the professional network of one of the authors. Table 1 provides a glimpse of the profiles of the 21 respondents. The work experience of the respondents ranged between 14 and 22 years. The respondents handled anywhere between 10 and 32 IT projects individually, $70 \%$ being cross border projects. We discussed the process with the panel and urged them to cooperate with us as it might require multiple rounds of iterations to achieve convergence in ranking.

Following Schmidt (1997), we asked each respondent to list the HRAPs that they considered important to successfully implement IT projects, subject to a minimum of six items. A total of 136 HRAPs were collated, as similar issues were addressed by the panellists differently. With the help of an English language editor, a unified description for each issue, considering the most commonly used phrases was generated. Wherever there was ambiguity or lack of clarity, the respondent was contacted and consensus achieved. For duplicate issues, the most common description was retained (Keil et al., 2013), so that we identified 44 unique HRAPs along with a brief description of each, from 21 respondents (see Appendix 1). 
In the second phase, each respondent was then provided with the randomly ordered list of 44 HRAPs along with a brief description, and then asked to select 20 HRAPs, in the order of preference that strongly influence IT project success (Schmidt, 1997). At this stage, three respondents did not carry on with the study, despite several reminders. Only those issues that were shortlisted by at least half of the respondents were retained and considered for the third phase (Schmidt, 1997; Watson, 2008). Table 2 depicts the sequence of the Delphi method.

\begin{tabular}{|c|c|}
\hline Discovering & $\begin{array}{l}\text { - } \text { Identification of } 21 \text { project managers and studying their profile } \\
\text { - Collection of } 136 \text { HRAPs along with brief description } \\
\text { - } \quad \text { Consolidation and verification of responses to capture fair representation } \\
\text { - Generating } 44 \text { unique issues after paring, removing duplicates and mapping of terms }\end{array}$ \\
\hline Determining & $\begin{array}{l}\text { - } \quad \text { Pared list of all } 44 \text { issues was randomly ordered } \\
\text { - Total participation at this phase was } 18 \text { respondents } \\
\text { - } \quad \text { Each respondent was provided with the list to select top } 20 \text { issues } \\
\text { - Twenty issues shortlisted by at least half of the respondents were retained } \\
\end{array}$ \\
\hline Ranking & $\begin{array}{ll}\text { - } & \text { List pared to } 20 \text { HRAPs for ranking by } 18 \text { panellists } \\
\text { - } & \text { Round - I ranking was based on the frequency of selection of each issue by panellists } \\
\text { - } & \text { Ordering of issues in rounds - II and III on feedback was based on mean ranks. } \\
\text { - } & \text { Kendall's W was calculated for each round, until an acceptable value was achieved. }\end{array}$ \\
\hline
\end{tabular}

Table 2: The three phases of Delphi method: discovering, determining and ranking

The third phase mostly involved ranking these 20 HRAPs by the same set of panellists, using an iterative process, until an acceptable level of consensus was achieved. Following Keil et al. (2013), the first round of ranking was based on the frequency of selection of each issue by the panellists. However, from the second round the ordering process was based on mean ranks, wherein the panellists were asked to rank each of the 20 HRAPs, in order of preference. They were also requested to write a brief note to justify their ranking procedure. Specific instruction was given to avoid tie ranking. Kendall's coefficient of concordance (W) was measured for each round to monitor improvement in agreement among panellists.

After achieving satisfactory consensus, we selected six panellists from PMI Mumbai chapter to further brainstorm the rationale behind selection of the HRAPs. With the help of semistructured interviews, we attempted to further investigate the following: (a) Why did some of these HR activities and practices emerge significant? (b) Are these activities and practices specific to India? (c) How do organizations effectively manage these issues? These responses were then compiled and also related to the literature. This enabled us to address RQ2.

To answer RQ3, we considered the top ten HRAPs as determined by the Delphi method as independent variables to design the questionnaire. The questionnaire was designed to collect data from respondents to develop a quantitative model. As all the questions were perception driven, a 5-point Likert scale was used for rating from excellent to poor. As discussed earlier, value-driven project management was captured by three outcome variables namely, meeting project goals, meeting customer goals, and meeting organizational goals, as documented by Shenhar et al., 2001).

As the objective was to determine the impact of the HRAPs on the three dimensions of project success, jointly, a simultaneous equations model (SEM) was applied. This helped to provide a comparative analysis of the independent variables and their concurrent impact on the outcome variables. This helped to develop a comprehensive picture by integrating the findings of the Delphi method and SEM, to address RQ4. Triangulation allows multiple viewpoints to study 
a single phenomenon by using a combination of methodologies that can include qualitative and quantitative research that can be used to achieve greater validation thereby enabling convergence of results (Jick, 1979; Joslin and Müller, 2016).

\subsection{Sampling, data collection and respondents' profile}

The members of the selected sample had a minimum of five years of fulltime work experience and also had attended a training program in IT project management. For data collection, one of the authors contacted 15 training centres that serve as PMI ${ }^{\circledR}$ Registered Education Provider (R.E.P.) and provide $\mathrm{PMP}{ }^{\circledR}$ certification preparatory courses.

QuestionPro was used as a platform for collecting online responses. In each of the centres there was a trainer responsible for coordinating and collecting the data. The questionnaire was circulated among 3750 potential respondents over nine months, from April 2015, of the PMI India Chapters of Mumbai, Delhi, Hyderabad and Bangalore. This process generated data of 431 observations, giving a response rate of $11.5 \%$.

\begin{tabular}{|c|c|c|c|c|c|}
\hline Variables & Categories & $\%$ & Variables & Categories & $\%$ \\
\hline \multirow{4}{*}{ Age } & Less than 25 & 11 & \multirow{2}{*}{ Gender } & Male & 86 \\
\hline & 25 to 28 & 38 & & Female & 14 \\
\hline & 28 to 35 & 33 & \multirow{6}{*}{$\begin{array}{l}\text { Project team } \\
\text { size }\end{array}$} & less than 5 & 19 \\
\hline & 36 and above & 18 & & less than 10 & 15 \\
\hline \multirow{4}{*}{ Education } & Graduate & 14 & & less than 25 & 29 \\
\hline & Post Graduate & 35 & & less than 50 & 15 \\
\hline & PMP/PRINCE certified & 22 & & less than 100 & 10 \\
\hline & $\begin{array}{l}\text { Other professional } \\
\text { training }\end{array}$ & 29 & & less than 1000 & 12 \\
\hline \multirow{6}{*}{$\begin{array}{l}\text { Project } \\
\text { category }\end{array}$} & Business Application & 42 & \multirow{6}{*}{ Designations } & Project Manager & 16 \\
\hline & Engineering application & 5 & & Project Leader & 14 \\
\hline & CRM & 5 & & Team Leader & 28 \\
\hline & ERP & 17 & & Quality Manager & 6 \\
\hline & Web application & 17 & & System Analyst & 12 \\
\hline & System software & 14 & & $\begin{array}{l}\text { Member, Development } \\
\text { Team }\end{array}$ & 24 \\
\hline
\end{tabular}

Table 3: Sample characteristics (sample size: 431)

As observed in Table 3, the age distribution of the respondents is skewed between 25 and 35, and the gender distributed towards males. This type of job is sometimes an impediment for female employees, given their family expectations in the framework of the Indian culture.

\section{Delphi findings}

The third phase of the Delphi study presents the ranking rounds, where the order of importance of the top ranked HRAPs emerged (Table 4). A total of three rounds of rankings were performed to achieve convergence among the respondents. All the 18 respondents participated for the first two rounds. The first round resulted in a Kendall's $W$ of 0.227 . Based on mean rank of each HRAP of the previous round, the second one generated a still lower Kendall's $W$ of 0.443 . Though the null hypothesis of no significant agreement was rejected at 95 percent level of confidence, we were interested in improving the value, further. 
Hence, we went for the third round. We received responses from 16 panellists. Two respondents dropped out due to outstation travelling. The Kendall's $W$ improved significantly to 0.732 . The correlation coefficient $(\mathrm{r}=0.716)$ indicated a very high agreement in ranking the 20 HRAPs. We informed the outcome to all 21 panellists. Though some authors (Brancheau and Wetherbe, 1987) argue that standard deviations also indicate consensus, following Schmidt (1997) we decided to ignore it as it does not apply to ordinal level data.

\subsection{People management skills of project leadership}

People management skills of project leadership emerged as the most significant issue in ensuring project success. Due to higher availability of jobs in emerging economies as compared to developed nations, employee attrition is higher (Agarwal and Mehta, 2014). Hence, people management is a crucial component of effective leadership. A leadership structure that is empowering and relies on participative decision-making processes, as well as engages project team members by creating a contributing environment (Keil et al., 2013; Zhu and Kindarto, 2016), is more preferred than autocratic processes with less delegation of authority.

\begin{tabular}{|c|c|c|c|c|}
\hline \multicolumn{2}{|r|}{ HRAPs } & $\begin{array}{c}\text { Round - I } \\
\text { Mean Rank }\end{array}$ & $\begin{array}{c}\text { Round - II } \\
\text { Mean Rank }\end{array}$ & $\begin{array}{l}\text { Round - III } \\
\text { Mean Rank }\end{array}$ \\
\hline 1 & People management skills of project leadership & 3.5 & 3.222 & 1.833 \\
\hline 2 & Effectiveness of project team communication & 8.889 & 7.556 & 3.944 \\
\hline 3 & Consultation with employees before assigning a project & 8.111 & 9.167 & 5.056 \\
\hline 4 & Job-matching to enhance performance & 10.111 & 8.278 & 5.778 \\
\hline 5 & Training of project leaders & 9.111 & 6.944 & 6.167 \\
\hline 6 & Extent of team member turnover & 9.167 & 9.167 & 7.111 \\
\hline 7 & Frequent conflicts among project team members & 9.222 & 8.444 & 7.444 \\
\hline 8 & Personnel turnover at organizational level & 9.444 & 8 & 8.444 \\
\hline 9 & Performance evaluation of individual members & 9.667 & 7.444 & 7.444 \\
\hline 10 & Listening & 9 & 9.5 & 9.389 \\
\hline 11 & Staff motivation & 10.5 & 9.667 & 11.112 \\
\hline 12 & Respecting Indian culture and ethnic diversity & 11 & 9.222 & 11.278 \\
\hline 13 & Creating congenial environment for sharing & 11 & 9.667 & 12.444 \\
\hline 14 & Making employees feel important & 11.056 & 10.167 & 13.001 \\
\hline 15 & Promoting a women-friendly work environment & 11.111 & 12.556 & 13.722 \\
\hline 16 & Embedding organizational core values in projects & 11.722 & 13.111 & 14.389 \\
\hline 17 & Promoting innovation & 11.389 & 16.444 & 15.944 \\
\hline 18 & Promoting formal risk management practices & 12.833 & 16.389 & 17.556 \\
\hline 19 & Building a global work culture & 15.833 & 17.5 & 17.722 \\
\hline 20 & Balancing standardization and customization & 17.333 & 18.111 & 18.778 \\
\hline & $W$ & 0.227 & 0.443 & 0.732 \\
\hline & $r$ & 0.181 & 0.41 & 0.716 \\
\hline
\end{tabular}

Table 4: Delphi method - ranking results from three rounds

Respondent 12 admits that the role of a project manager as a leader is often a tightrope walk. $\mathrm{S} /$ he has to maintain the right balance between project team members and management. $\mathrm{S} / \mathrm{he}$ has to ensure that the project goals are aligned with organizational goals. In sarcastic terms, s/he said: 
"Without the 'blessings' of the top management and the HR department, often the project manager is like a commander of the army without a sword. Having said that, the higher the distributed leadership, higher the delegation of responsibilities more is perceived ownership and urge to perform."

All panellists unanimously agreed that a significant component of project leadership is communication and people management. In fact, leadership quality is often judged by the ability to manage people and communicate. Humility in all forms of communication, compassion to team members and ethical behaviour would ensure the right leadership traits.

\subsection{Effectiveness of project team communication}

Similar to the outcome of Keil et al., (2013), effective project team communication emerged as the second most significant HRAP. Team communication unfolds the barriers to project complexity and the interdependencies across various stakeholders to ensure value-driven project management (Kennedy et al., 2017). Respondent 2, who ranked it highest, said:

"Frequent conflicts originate from poor communication among team members. The project leader plays an important role over here. S/he has to live by example. Often, informal settings like a dinner party, family gatherings, playing indoor games that involve teamwork enhance communication within team members. Indians come from varied backgrounds and ethnic cultures - integrating the entire team is a task in itself."

Respondent 4, who also ranked this issue highest said:

“...Often when everything is set and project scope is well-defined a wild request comes from the customer to incorporate changes based on a new technology that has been just launched. To ensure customer delight, yet not overrunning the project constraints, communication is the key to success."

In this way, it emerged that quality of the communication is of paramount importance not only in the critical phase of planning of the project, but also in dealing with emergencies and variations required by the customers.

\subsection{Consultation with employees before assigning a project}

This emerged as the third most important variable. Respondent 12 puts it thus:

"The decision about an employee joining a project team is a two-way traffic. It is like a marriage between two parties. Both need to like each other and there has to be a certain amount of synergy within fellow team members to work together to achieve a certain goal. After all, we all represent the organization."

Respondent 2 who faced a situation where her competencies were misrepresented while assigning a project, shared:

"We do not stick to the same competencies lifelong. We acquire new skills and sometimes abandon the earlier ones, sometimes due to obsolescence. This is truer in the case of IT projects. Hence, a prior consultation and a candid discussion can be helpful. Also, once I am assigned with a project, it does not go well, if I reject it. Hence, a mutual consent works well."

Consultation with employees before assigning a project goes therefore beyond the symbolic meaning of establishing a connection and building consensus around common objectives. Hence, in the IT sector, consultation becomes critical in building different team competences. 


\subsection{Job-matching to enhance performance}

Most of the respondents who ranked consultation with employees before assigning a project, very highly also ranked this issue favourably. Job-matching can be considered as a typical HRAP under the responsibility of resource and delivery managers to ensure enhanced performance (Santos et al., 2013). As respondent 17 puts it aptly:

"Job matching is not the same as competency mapping. Job matching is ex-post and competency mapping is ex-ante. Often, there is a time lag, due to which there could be discrepancies between the two. Both are important while assigning an employee with a project, improper job matching originating from ignoring competency assessment can adversely affect project performance."

Thus emerged the necessity to have a coherent alignment between the competencies detailed by each project team member and the job that is assigned to the person. IT, being an industry where expectations of customers can be very demanding and sometimes disrupting, to have the right person in the right role is a key asset for the success of a project.

\subsection{Training of project leaders}

Coetzer and Gibbison (2016) discuss the importance of the HR department's encouragement to spend intensive time on project management training for project managers and team members by using organizational coaches and peer coaching. A few respondents ranked this issue as having highest importance. Respondent 7 argued:

"If project leaders are not well trained and abreast with the latest innovative technologies in the IT domain, there is nobody to look up to."

Respondent 17 stated:

"Even if the management does not train its employees regularly, it is imperative that the project managers are well-trained and they are aware of the state-of-the-art technological advancements. As per my experience, project managers are always keen to train their teams as it helps them to bond and also enrich their own learning and experience..."

Technical training of project leaders is indeed a key issue in IT project success, before assigning a project. The project leader is often expected to train his team members, especially when time is limited and the possibility of sending a member for external training is ruled out.

\subsection{Extent of team member turnover}

Considering the importance of factors that influence team member turnover in emerging economies, various researchers have discussed this aspect in greater detail (Zhou, et al., 2010). A host of factors including culture shock, remuneration disparity, perquisites, benefits as compared to industry standards, work environment, sense of ethics and distributive justice, other lucrative opportunities, and so on, play important role in team member turnover (Carr et al., 2010). Respondent 2 while expressing her/his concern said:

"We all work in our respective project with a lot of passion. Very often we work extended hours to coordinate across diverse time zones and meet client specifications. Suddenly, when we come of know about a dear colleague and friend leaving, it hurts. Seldom have I seen organizational efforts to retain the best talents."

On similar lines respondent 8 said: 
"Good people learn fast and move on. They believe working in the same place for long hinders career growth. Eventually, we are left with a set of incompetent people who rise to the top, not because of their performance, but for their so-called loyalty to the organization."

\subsection{Frequent conflicts among project team members}

Jiang et al. (2014) discuss how good understanding among team members that is aligned with overall organizational and IT project goals can lead to agreement in decisions through conflicts. Butler (1973) in his iconic research urges organizations to perform systematic analysis to identify the root causes and extent of implications of dysfunctional conflicts in projects initiating from unhealthy competition and personal vested interests. Most of the respondents agreed that a certain degree of conflict is often inevitable while working on projects with stringent deadlines and constraints. As respondent 17 put it:

"There are two types of conflicts, as I see it - constructive and destructive. A constructive conflict is always healthy as that enhances performance in the long run, if not the short run. Destructive conflicts are mostly led by personal agenda. I have been a victim of such animosity."

Respondent 2, quite contradictory to the earlier argued:

"Conflicts can arise from very small things if team members do not resonate the same vibrations. Then conflicts can originate from ways in completing tasks, approach in handling customers' queries, or fighting with limited resources."

As in other contexts, the existence of a conflict here does not represent a problem in itself. On the contrary, if the conflict is focused around an object related to the project (managing tasks, handling customers, etc.), the exchange of different views generates better solutions. When instead, the conflict is centred on relational issues between people, then it might become counterproductive of the achievement of the results.

\subsection{Personnel turnover at organizational level}

Abdel-Hamid (1992) discussed how turnover at the top management level can result in serious instability in IT projects and disrupt succession planning, leading to schedule and budget overruns. Parker and Skitmore (2005) argue that turnover of management personnel happens mostly because of misalignment of organizational culture, alternative career options and personal growth opportunities. Respondent 12, while speaking from her/his experience said:

"When there is a turnover at team member level, it is not difficult for a project to recover and return to its equilibrium path. However, turnover at organizational level creates a black hole. When my project sponsor resigned, it left the project rudderless. As a young project manager, I used to look up to him for advice and guidance. It not only reduced the overall morale of the project team, but the confidence of the client was also shaken."

Respondent 4, who is a Quality Manager said:

"Resignation of a top management executive can often have long term and irreparable damage to the organization. Within my limited experience, I have observed that when a senior leader motivates, nurtures and personally takes interest in a particular vertical of business, his departure impacts the company's bottom line." 
While this issue is not of topmost importance, several panellists raised concerns on organisational turnover at the top management level, given that such incidents not only impact organizations but also projects.

\subsection{Performance evaluation of individual members}

Frederiksen et al., (2017) argue that employees who work in complex project environments are generally evaluated by the project managers or supervisors. However, this is often subjective in nature leaving scope for dissatisfaction among team members. Respondent 8 said:

"A just structure for performance evaluation is a myth. It is rarely just. However, what makes it just and ethical is the transparency. Also, having guidelines for performance evaluation is not enough - its implementation is equally important. It should be free from subjectivity, to the extent possible."

On a very practical note, respondent 2 said:

"The organization should have the courage to demonstrate transparency in performance evaluation - it should be process driven. This could lead to heart-burn and attrition of valued employees. However, any compromise in this aspect just to retain an employee would jeopardise the whole effort."

This highlights the need of having an assessment system not only accurately designed, but also supported by a process properly carried out (Katou et al., 2014). This is of great criticality, as the implementation of performance assessment has a cascading effect on other HRAPs such as remuneration, training, promotion, etc.

\subsection{Listening}

According to Keil et al., (2013), extending a patient hearing to project teams' concerns helps understanding project dynamics, associated risks, management of client expectations, and so on. Respondent 12, a project leader rightly put it:

"Listening to my team members helps me solve half the battle. However, it is important that I am compassionate and feel for their emotions. If I don't care a damn about their feelings and emotions, it impacts the project outcome. Everything is interrelated."

Respondent 5, who is a development team member opines:

"I guess I love my work and I'm a silent worker. Nevertheless, I often want my teammates to hear me. I want my team lead to ask me what I do and how I do, or whether I am facing any problem. Sometimes, when work gets monotonous, I wish we can chat for a while and then again get back to work. I guess, the art of listening is an attribute of a giver."

These evidences show the importance of developing relational competencies including the capability of establishing empathy with the members of the project team. While this is not so unexpected, it is interesting to note that such an emotional skill is perceived as a key element of success for managers of IT projects - a context in which usually high expectations exist in relation to the technical and managerial dimensions of the role.

\subsection{Other factors}

The top ten HRAPs ranked in the Delphi method study have specific relevance to the Indian context. So, in order to address RQ2, we can infer that the most significant HRAPs that IT 
companies should consider are local in nature. While is it agreed that some of these HRAPs have reference in literature in some form, there specific Indian dimensions to each of these. There are a few other factors which did not figure in the top 10, but are given importance by several panellists. These include, respecting Indian cultures and ethnic diversity, creating a congenial environment for sharing, making employees feel important, and promoting a women-friendly work environment.

Respondents expressed the need for creating a camaraderie feeling among team members that can improve productivity. Purvanova (2013) discusses the need for creating a congenial environment that promotes fellow-feelings among team members. A respondent said:

"After all, we spend most of our precious time with our colleagues. So why not consider it as our second home - our second family? If that is possible, interpersonal trust, reliance, interpersonal learning, sharing without inhibitions can happen spontaneously."

Respondent 8 emphasized:

"You don't need to be too intelligent to fathom if your organization is employeefriendly. I think making you feel important is the primary factor. How can I give my $100 \%$ if I perceive that I am not important over here? The organizational culture percolates to the project manager. When I was a team member, I felt proud that my contribution was appreciated. I felt important. Today, I treat my team members similarly. However, that does not imply that I will promote mediocrity."

Respondent 2, a woman project leader said:

"I wouldn't have been able to work at ... (company name withheld), unless the organization was empathetic to its women employees. Ours is a patriarchal society. Many a times, the responsibilities at home do not reduce, even if we earn a handsome salary and support the family. I am allowed flexible working hours. There is a crèche at my workplace. I leave my little daughter over there and can concentrate on my work. Whenever required I can visit her during office hours. Such facilities create a difference."

Though respondents spoke about organizational values and work culture, they did not rank any of these issues with topmost priority. Some spoke about the organization's role in promoting innovation, but did not rank it as a significant trait under HRM. They argued that risk management is a technical or operational requirement for implementing a project rather than including it as an important issue under HR activities and practices.

\section{Quantitative model}

\subsection{Measures}

To address RQ3, we used a quantitative model. Shenhar et al. (2001) identify 13 constructs to derive four dimensions to measure project success. The four dimensions are project efficiency, impact on the customer, business success, and preparing for the future. Based on the geographical context, research scope and informal discussions with panellist of the Delphi method, we adapted ten constructs from the 13, with minor modifications. These ten constructs formed the basis of outcome variables. Ten mono-item constructs, identified from Delphi method were considered as independent variables. A questionnaire was constructed 
to capture data from 431 respondents. They were asked to indicate on a 5-point Likert scale (1 implying poor and 5 implying excellent) how they rated each of these constructs with reference to their workplace experience. Each of these 20 constructs were presented in the form of statements, e.g. "The project that you are currently associated, tends to meet operational specifications." The respondent was required to tick the most appropriate option in the 5-point Likert scale.

In order to reduce the outcome variables, an exploratory factor analysis was performed. This helped converting the ten constructs to three dimensions (see table 5). These three factors were treated as multi-item constructs to capture IT project success. Table 5 reports all the constructs that form the outcome and independent variables for the quantitative model. The results of exploratory factor analysis after Varimax rotation for the three multi-item constructs are above 0.70 (three items fall short, though). Reliability is achieved with Cronbach's alpha values higher than 0.70 , as well.

Confirmatory factor analysis (CFA) was also performed to check convergent and discriminant validity. The goodness of fit indicators indicate that the model fits well with observed data $\left(\chi^{2}\right.$ $=196.582, \mathrm{p}<0.001$, goodness of fit index $(\mathrm{GFI})=0.971$, comparative fit index $(\mathrm{CFI})=0.985$, root mean square error of approximation $($ RMSEA) $=0.048$ and PCLOSE $=0.000$ ). The results with two factors was worse, hence, the above was considered. Though statistically significant $\chi^{2}$ does not ensure a good fit of model, in larger samples with over 10 observed variables, significant p-values can often be expected (Hair, et al., 2010). To ensure convergent validity, average variance extracted (AVE) of each factor was calculated. The values were above recommended cut-offs (Hair, et al., 2010). Factor loadings from CFA and AVE exceeded 0.50 cut-off, which ensured convergent validity (Hair, et al., 2010).

We found that the minimum correlation $(\min r)$ for each factor was statistically significant and higher than any other maximum correlation ( $\max r$ ) associated with the variables of other factors. It was also observed that the square root of AVE was larger than the correlations between a particular construct and other constructs. This ensures discriminant validity.

Project goals were measured in terms of operational performance and technical performance and meeting cost and schedule targets. Customer goals as visualized by the end user or customer were captured by addressing their changing needs, amicability of usage of the end product and overall satisfaction. Lastly, organizational goals were measured in terms of achieving commercial success, gaining market share and meeting overall organizational mission. 


\begin{tabular}{|c|c|c|c|c|}
\hline $\begin{array}{c}\text { Success Dimension } \\
\text { (multi-item } \\
\text { constructs) }\end{array}$ & Success Measures & $\begin{array}{l}\text { Standard- } \\
\text { ized } \\
\text { loading } \\
\end{array}$ & $\begin{array}{l}\text { Average } \\
\text { variance } \\
\text { extracted }\end{array}$ & $\begin{array}{l}\text { Construct } \\
\text { reliability }\end{array}$ \\
\hline \multirow{4}{*}{$\begin{array}{l}\text { Meeting Project Goals } \\
\text { (MPG) }\end{array}$} & Meeting operational specifications & 0.668 & \multirow{4}{*}{0.615} & \multirow{4}{*}{0.841} \\
\hline & Meeting technical specifications & 0.777 & & \\
\hline & Meeting schedule targets & 0.715 & & \\
\hline & Meeting cost targets & 0.893 & & \\
\hline \multirow{3}{*}{$\begin{array}{l}\text { Meeting Customer } \\
\text { Goals (MCG) }\end{array}$} & Fulfilling changing customer needs & 0.681 & \multirow{3}{*}{0.781} & \multirow{3}{*}{0.903} \\
\hline & Ensuring usability of product & 0.876 & & \\
\hline & Enhancing customer satisfaction & 0.787 & & \\
\hline \multirow{3}{*}{$\begin{array}{l}\text { Meeting } \\
\text { Organizational Goals } \\
\text { (MOG) }\end{array}$} & Achieving commercial success & 0.697 & \multirow{3}{*}{0.511} & \multirow{3}{*}{0.774} \\
\hline & Gaining increased market share & 0.792 & & \\
\hline & $\begin{array}{l}\text { Aligning with overall organizational } \\
\text { priorities }\end{array}$ & 0.766 & & \\
\hline
\end{tabular}

Table 5: Basic statistics of constructs forming outcome variables

\subsection{Quantitative model}

To address RQ3, we used a simultaneous model - the Full Information Maximum Likelihood Estimation (FIMLE) method to evaluate the impact of the ten independent variables (monoitems). The rationale behind selecting FIMLE is manifold. Firstly, it is a simultaneous equations model that allowed us to consider three output variables and ten independent variables. Secondly, after collection of data it was discovered that there were missing values. Multiple imputation and FIMLE are generally used in such cases. While imputation methods replace or imputes missing values, FIMLE estimates population parameters that would produce the most likely estimates from analysed sample data (Collins, Schafer and Kam, 2001). FIMLE allowed sorting missing data in a specific pattern, so that the rows that contain missing values are estimated together. It is a systems method of estimation and uses information of the endogenous variables effectively. Thirdly, as FIMLE takes into account the error covariances across equations, it is also asymptotically efficient, in the absence of specification error. Hence, we used FIMLE model to analyse how HRAPs influence value-driven project management, i.e., meeting project goals $(M P G)$, meeting customer goals (MCG) and meeting organizational goals (MOG), as discussed in Table 2 .

The $j^{\text {th }}$ equation of the model can be represented as follows:

$\varphi_{j}\left(Y_{1}, \ldots, Y_{J}, X_{1}, \ldots, X_{N}, \beta_{g}\right)=U_{j}[j=1, \ldots, J]$

... equation $(i)$

where, $Y_{j}$ are the endogenous variables, $X_{j}$ are the predetermined variables $\beta_{g}$ is a vector of unknown parameters and $U_{j}$ is the disturbance term.

The FIMLE of the unknown parameters in equation (i) can be obtained by maximizing $L$ following Chapman and Fair (1972), using EViews 9.0 software:

$L=-\frac{1}{2} \ln |2 \pi|-\frac{1}{2} J \ln |\theta| \frac{1}{2} \operatorname{Jr}\left\{\theta^{-1}(Y-X \pi)^{\prime}(Y-X \pi)\right\}$, with respect to the variance-covariance matrix of the structural form disturbances, where, $\pi$ represents the reduced form parameters, $J$ denotes the total number of observations, $\theta$ denotes the variance-covariance matrix of the reduced form disturbances, $r$ denotes the restrictions. At this backdrop, the equations in the FIMLE model can be represented as follows: 
$M P G=\alpha_{0}+\alpha_{1} X_{1}+\alpha_{2} X_{2}+\alpha_{3} X_{3}+\ldots+\alpha_{n} X_{n}$

.... equation (ii)

$M C G=\beta_{0}+\beta_{1} X_{1}+\beta_{2} X_{2}+\beta_{3} X_{3}+\ldots+\beta_{n} X_{n}$

.... equation (iii)

$M O G=\gamma_{0}+\gamma_{1} X_{1}+\gamma_{2} X_{2}+\gamma_{3} X_{3}+\ldots+\gamma_{n} X_{n}$

.... equation (iv)

FIMLE could have been conducted with different coefficients of the predetermined variables across all the equations. However, as there was no much difference in results, it was avoided.

As the number of predetermined variables in each equation is exactly the same as the number of predetermined variables in each equation, the system of equations can be considered as exactly identified. FIMLE is often when data contains missing values, as it uses raw data as input, as opposed to the observed covariance matrix, which contains less data (Graham, 2009). The system of equations evaluates the influence of the selected HRAPs on the three dimensions of project success.

\begin{tabular}{|c|c|c|c|c|}
\hline HR activities and practices (independent variables) & MPG & MCG & MOG & Tolerance \\
\hline People management skills of project leadership & $\begin{array}{l}0.6757^{* *} \\
(0.0109)\end{array}$ & $\begin{array}{l}0.6542^{* *} \\
(0.0103)\end{array}$ & $\begin{array}{l}0.6521^{* *} \\
(0.0106)\end{array}$ & 0.7463 \\
\hline Effectiveness of project team communication & $\begin{array}{l}0.5232^{* *} \\
(0.0413)\end{array}$ & $\begin{array}{l}0.4617^{* *} \\
(0.0339)\end{array}$ & $\begin{array}{l}0.4740^{* *} \\
(0.0488)\end{array}$ & 0.6592 \\
\hline Training of project leaders & $\begin{array}{l}0.4574^{* *} \\
(0.0465)\end{array}$ & $\begin{array}{l}0.3596^{* *} \\
(0.0483)\end{array}$ & $\begin{array}{l}0.4198^{* *} \\
(0.0476)\end{array}$ & 0.8329 \\
\hline Job-matching to enhance performance & $\begin{array}{l}0.4324^{* *} \\
(0.0472) \\
\end{array}$ & $\begin{array}{l}0.4200^{* *} \\
(0.0481) \\
\end{array}$ & $\begin{array}{l}0.4144^{* *} \\
(0.0489)\end{array}$ & 0.5658 \\
\hline Consultation with employees before assigning a project & $\begin{array}{l}0.3789^{* *} \\
(0.0599)\end{array}$ & $\begin{array}{l}0.2423^{*} \\
(0.0615)\end{array}$ & $\begin{array}{l}0.3664^{* *} \\
(0.0603)\end{array}$ & 0.5381 \\
\hline Listening & $\begin{array}{l}0.2188^{*} \\
(0.0796)\end{array}$ & $\begin{array}{l}0.2187^{*} \\
(0.0716)\end{array}$ & $\begin{array}{l}0.2003^{*} \\
(0.0797)\end{array}$ & 0.4546 \\
\hline Frequent conflicts between project team members & $\begin{array}{l}-0.2122^{*} \\
(0.0876) \\
\end{array}$ & $\begin{array}{l}-0.1948^{*} \\
(0.0882) \\
\end{array}$ & $\begin{array}{c}-0.1817^{*} \\
(0.0894) \\
\end{array}$ & 0.4621 \\
\hline Extent of team member turnover & $\begin{array}{l}-0.1604^{*} \\
(0.1037)\end{array}$ & $\begin{array}{l}-0.1503 \\
(0.1043)\end{array}$ & $\begin{array}{l}-0.143 \\
(0.1056)\end{array}$ & 0.5061 \\
\hline Performance measurement of individual members & $\begin{array}{l}0.1672^{*} \\
(0.0845)\end{array}$ & $\begin{array}{l}0.1218 \\
(0.1112)\end{array}$ & $\begin{array}{l}0.1444 \\
(0.1086)\end{array}$ & 0.4389 \\
\hline Personnel turnover at organizational level & $\begin{array}{l}-0.1231 \\
(0.1275)\end{array}$ & $\begin{array}{l}-0.1217 \\
(0.1283)\end{array}$ & $\begin{array}{c}-0.1694^{*} \\
(0.0871)\end{array}$ & 0.4714 \\
\hline Adjusted R-Squared & 0.3903 & 0.3649 & 0.3474 & \\
\hline
\end{tabular}

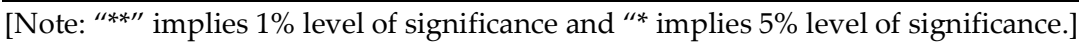

\section{Table 6: FIMLE output}

As observed from the results in Table 6, the three outcome variables are impacted significantly by the independent variables, though differently. Typically, a tolerance below 0.30 would imply a multicollinearity problem (Hair, et al., 2010). In this case, all the independent variables have a tolerance value higher than 0.30 (table 6). In general, the HRAPs have the highest influence on project goals (adjusted R-Squared 0.3903), followed with meeting customer goals 
(adjusted R-Squared 0.3649) and a trickling down effect on meeting organizational goals (adjusted R-Squared 0.3474). This also implies that project success is not about meeting project goals, alone. Value-driven project management has a significant impact on meeting customers' goals and the goals of the organization. This is the one of the principal contribution of this study.

People management skills of project leadership have the highest impact on the outcome variables. People management skills of project leader have a direct positive impact on project goals, more than the customer and organizational goals. On similar lines, Effectiveness of project team communication has a higher impact on the immediate team that is dealing with the project. The percolation of effective communication is equally relevant for customer interactions and meeting their expectations, and last but not the least, it has a positive impact on organizational goals, as well.

Training of project leaders emerged as the third most impacting variable. It has the highest impact on project goals. The organization reaps the benefits of training project leaders across several projects, whereas the benefits to the customer are limited to a single project. The results show that training project leaders impacts organizational goals more than customer goals. We find that it is important to ensure that project requirements match with the competencies of the project team member. If job-matching is ensured, it has a significant contribution to project goals. In addition, the impacts on customer and organizational goals are no less.

The study also finds that merely matching competencies with project requirements is not enough. It is important to consult with employees, before assigning a project. Hence, if there has been a healthy consultation with employees before assigning a project, it has a high influence on the project goals. However, mostly such misalignment does not influence the customers.

Listening to project team members on issues related to the project and beyond the scope of the project influences all the three outcome variables more-or-less equally. In line with Roebuck et al., (2015), we find that Indian male project managers are less attentive in terms of listening skills than female managers. Project managers and higher authorities need to be careful about frequent conflicts among project team members. This adversely impacts value-driven project management at all levels. Team member turnover also adversely impacts the immediate project goals. However, it does not impact the customers or the organization in the long run. Tripathi (2014) argues that reducing member turnover in project teams is one of the most important issues that the Indian IT sector encounters. High attrition rates manifest in the form of budget and schedule overruns. By contrast, personnel turnover at the organizational level affects organizational goals, leaving project and customer goals unaffected. Performance measurement of individual members of the project team did not emerge as a significant variable, other than impacting project goals at $5 \%$ level of significance. This implies that organizations have timetested and robust HR processes for performance evaluation.

\section{Discussion}

The current study is focused on the features associated with HRAPs in Indian IT projects and their impact on project success. With the changing environment, firms are embracing a transition to project based organizations. This metamorphosis is redefining the role of HR to create a new work environment that can efficiently connect projects with team members, and align with dynamic customer needs and organizational goals and culture (Gareis, 2013; Keegan et al., 2012). With this backdrop, the major contribution of this study is that HR factors 
impact project goals more than customer goals and organizational goals. This reinforces the fact that from an organizational perspective, the diversified aspects of HR that impact project outcome cannot be considered in silos.

\subsection{Triangulation}

As proposed, the study has used a multi-method strategy to evaluate the impact of HRAPs on value-driven project success. The 16 panellists' responses not only help understand the significance of the finally shortlisted HRAPs, but, also provide the India-specific approach as compared to global experience. Though the panellists provide India perspective responses to all the ten factors, there are certain elements that emerge unique to the Indian cultures and values. For example, giving the employee equal right to select a project or join a project team for a new project is practically non-existent in India, while well-practiced in the Western world. A well-structured mechanism to ensure free-flow of communication at all levels is comparatively weak in India, as compared to the Western world. Also, in India, as opposed to the Western world, people management processes practiced by project leadership is considered as an art, without having a scientific process that could govern it. Also, it is seen that assessment systems are more ad hoc in nature, as compared to well-designed systems and processes practiced in most of the Western world. This answers RQ2.

The measurement of triangulation can be considered to be successful if the results of the ranking of Delphi from 21 panellists match with the findings of the FIMLE model. While the purpose of the Delphi method was to rank the most significant HRAP that impacts project success, the purpose of FIMLE was to critically evaluate the influence of the top ten HRAPs derived from Delphi on value-driven project success. The first two variables namely People management skills of project leadership and Effectiveness of project team communication have the same order of influence on project success. In the Delphi method, Consultation with employees before assigning project and Training of project leaders were ranked third and fifth. In the FIMLE model they interchanged their ranking. Job-matching to enhance performance ranks fourth in both the methods. Listening skills, which was the last ranked variable in Delphi, emerged as the sixth most influential variable in the FIMLE model. This is a significant deviation among the two methods. Extent of team member turnover, which ranks sixth in Delphi ranks eighth in the FIMLE model. Frequent conflicts among project team members, ranks seventh in both the methods. Turnover at organizational level is eighth in Delphi, but emerges significant only in meeting organizational goals in the FIMLE model. Performance measurement of individual members ranks ninth in both the methods. However, for FIMLE, it impacts only at the project level and not at the customer or organizational levels. Hence, broadly we can state that except for a couple of cases, the results of the Delphi and the FIMLE techniques are mostly synchronized. The triangulation of the findings from multi-method research thus provides a comprehensive response to RQ4. Based on findings, we can infer that it is possible to develop a comprehensive picture that can triangulate the findings from multi-method strategies with converging outcomes.

\subsection{Theoretical contribution}

The present study contributes to the literature of project management and HRM in different ways. First, from a methodological point of view, this study is one of the few to consider a simultaneous equations model with multiple outcome variables to investigate the impact of HRAPs developed from a Delphi technique on value-driven IT project management. Second, while shortlisting twenty top ranked HRAPs from a total of 136 measures that are globally 
acceptable (RQ1), we were able to distinguish the top ten HRAPs that are more relevant to the Indian IT projects (RQ2). Third, this is one of the few studies that consider project success from the viewpoint of three major stakeholders that helped to capture the differentiated impact of HRAPs on project, customer and organizational goals, using the FIMLE simultaneous system of equations. Though no major difference in the adjusted R-Squared of the three equations of the FIMLE model emerged, this study shows that HRAPs have the highest influence on project goals, followed with customer and then, organizational goals (RQ3). This means that valuedriven project management is not about the project alone, but also about meeting customers' expectations and organizational goals. Last, in the methodological triangulation of the results generated from the Delphi method and simultaneous equations model, there was sufficient evidence to believe that there was congruence in the findings from the qualitative and quantitative models, thereby claiming successful triangulation (RQ4).

More specifically, in relation to "How do the most important HR practices influence valuedriven project success" (RQ3), we find that good people management skills of project leadership, project team communication, training of project leaders, maintaining currency and competence, job-matching to improve performance and effective listening skills are certain key HRAPs that positively impact project goals. These factors also play crucial roles in meeting customer goals and organizational goals, albeit weaker than meeting project goals. These results point to the fact that a mix of harder HRAPs (e.g., job-matching to improve performance), mixed with soft ones (e.g., effective listening skills) need to be combined in order to ensure the success of IT projects. Partially not expected, team member turnover adversely impacts only the project and not the customers or the organization, as a whole. This output is only somehow consistent with Weimann et al. (2013) who discuss how personnel turnover at organizational level can adversely impact project performance, and in turn, lead to customer dissatisfaction. Similarly, attrition at the top management level has little impact at the project level or clients. The results of the study also underlined the importance of managing conflicts as they might adversely impact at all levels, though not strongly.

\subsection{Managerial implications}

The findings of our study point alto to several managerial implications. Whereas from the researchers' point of view, the results tend to validate the influence of a set of HR applications and practices (HRAP) on IT project management, for HR professionals, this study provides crucial information on context-specific nature of HRAP which can be used to develop new HR schemes and policies for IT project-oriented organizations. While the study is typical to the Indian business environment, many of the findings are applicable to other emerging economies like, Philippines, Vietnam, Malaysia, Mexico, Thailand, etc., where HRAPs require further streamlining.

Similarly interesting are the insights for both project leaders and HR managers in Indian IT organizations. Though developments in HRM are well documented in literature, its link with IT project-oriented organizations and value-driven project success is rare. Our results point at four most significant elements for efficient HRAP in IT projects that not only impact the project, but also customer and organizational goals, to ensure value-driven project management. These are people management skills of project leadership, team communication, training of project leaders, ensuring job-matching and listening to team members' issues. Often, in Indian IT firms, the project leadership is technically sound and highly result-oriented, though low on managing people. We suggest that potential leaders should be identified early 
and their training should actively include people management and the criticality of effective communication to enable project members to work in teams, amicably. The softer skills are often ignored in IT projects, as technology takes precedence (Carson and Kelly, 2015). This has adverse long-term impact on project, customers and organisation. It is also not uncommon in Indian IT firms to allocate employees projects, not because they specialize in the areas, but, because there are vacant slots to be filled. While this help in short-term gains in ensuring labour utilization and saturation, however, in the long term it adversely impacts organizational commitment of employees, thereby leading to reduced productivity. Such acts can potentially lead to employee turnover, which is another significant challenge that the HR deals with, in India. Also, project leadership has to take a crucial role to reduce frequent team conflicts, by opening the doors of smooth communication. Both, frequent conflicts among team members and employee turnover negatively impact IT project success. Although there is no simple recipe to ensure project success, undoubtedly effective HRAP plays a vital role in motivating project team members to promote value-driven project management.

Efficient HRAPs not only positively impact projects, but also other stakeholders like customers and organizations. This is particularly true for IT projects, which are often highly technology driven and are frequently subject to change in project scope (Sutterfield et al., 2006). Clearly, this calls for a transition of HR from traditional roles to roles that integrate all stakeholders who are directly or indirectly associated with the project, in order to achieve value-driven success (Stulgienè and Čiutienė, 2012). It is a tightrope walk to ensure the right balance of leadership, communication, motivation and also managing conflicts and turnover; leading to project success on one hand, and gaining the confidence of team members, customers and organization, on the other (Todorović et al., 2013).

In India, unlike the developed countries where responsibilities are streamlined and agendadriven, HRAP is often inclusive of technical managers and IT project leaders. In most cases, these managers and leaders work hand-in-hand with HR and take personal interest in selection, recruitment, assessment of employees, training, diffusion of the culture of the company, and team building. This is in addition to their regular managerial activities. In such situations, it is therefore favourable to replicate what many medium-sized or even large organizations do by using HR generalists to help execute projects and align with organizational goals, as well. HR department can focus on employee training and motivation schemes that can include enhancing knowledge and skills for better performance. A major deficiency noted in Indian IT project management is lack of listening to employees' grievances, especially when there are conflict between team members or with project seniors. Often lending a patient hearing to employees' problems and being empathetic, can provide solace and inspire them. Motivating team members can potentially solve team conflicts and enhance team communication and project performance (Claudia, 2010). Effective communication also includes consultation with employees before assigning a project. The hierarchy-based Indian work culture often restricts leaders to consult with employees. Such consultations can reduce significant burden of team members and project manager. The role of the HR department in major decisions of promotions or transfers should be in conjunction with project managers to ensure project team cohesiveness and effectiveness, thereby effectively managing attrition. In other words, the HR department can not only be an effective watchdog but also the ringmaster in empowering project leadership, thereby keeping a vigilant eye on the alignment of project goals with client requirements and organizational vision to ensure inclusive growth, in that becoming a true business partner. 


\section{Conclusions}

In this study we adopt a multi-method research methodology. The Delphi method is used to identify the top 20 HRAPs that influence the success of value-driven project management in India in terms of meeting project, customer and organizational goals. Using a multi-method research approach, we also attempt to check for triangulation and achieve reasonable convergence. The results show that efficient project leadership, effective communication, relevant training, listening to team members, and avoiding conflicts and turnover are some of the crucial HR practices that can help in attaining value-driven project management. Also, the immediate impact of effective HRAPs is on the IT project; the impact on meeting customers and organizational goals comes next. The study clearly depicts that the global best practices in HRAP cannot be blindly followed in India; special consideration to customs, cultures, geographical and demographic diversity requires customized approach to HR for effective results in IT projects. The use of self-assessed scales in developing the questionnaire for the quantitative model might raise common problems of method variance, though they all show proper psychometric capabilities. However, we argue that the triangulation approach largely takes care of the validity issues. Moreover, our study focuses on HRAPs and their influence on value-driven project management. Impact of other factors that are project-specific (e.g., technical knowhow, tools and technology, project estimation and planning, gold plating, etc.), organizational (e.g., lack of managerial commitment, organizational structure, reward mechanism, leadership strategies, linking project to business objectives, cross-department knowledge sharing, etc.) or environmental (e.g., inadequate third party performance, working with contractors and sub-contractors, change of project scope, cross cultural issues, business uncertainty, etc.) are ignored in which can have significant influence of project performance (Uzzafer, 2013). Finally, the study concentrates on a specific geographical context - Indian IT projects. A comparative analysis across different countries with a cross-border perspective can be very enriching in validating the results and revealing newer dimensions of research.

Our research is certainly not free from limitations. This provides scope for future studies. This study is cross-sectional in nature and this limits the possibility for rigorous testing of the causeand-effect relationship between the independent and outcome variables, across time periods. A longitudinal study that can incorporate the managerial implications of the current findings on the functioning of HR departments of IT project-based organizations can potentially derive interesting outcomes. A study using randomized control trials with control groups where the HR department get no inputs for improvement and the other that receives the experimental treatment based on the findings of this study, can effectively test the influence of HRAPs on IT project success.

\section{References}

Abdel-Hamid, T.K. (1992), "Investigating the impacts of managerial turnover/succession on software project performance". Journal of Management Information Systems, Vol. 9 No. 2, pp. 127-144.

Agarwal, R. N., \& Mehta, A. (2014). Impact of performance appraisal and working environment on the job satisfaction and attrition problem in the Indian IT industry. Paradigm, 18(1), 73-85. 
Basten, D., Joosten, D., Mellis W. and Wallmueller, C. (2014), "Keep IT simple-the challenge of interlaced IT architecture at Gothaer Systems". Journal of Information Technology Teaching Cases, Vol. 4 No. 1, pp. 34-40.

Bathallath, S., Smedberg, А̊, \& Kjellin, H. (2017). Impediments to Effective Management of Project Interdependencies: A Study of IT/IS Project Portfolios. Journal of Electronic Commerce in Organizations (JECO), 15(2), 16-30.

Batistič, S., \& Kenda, R. (2018). Toward a model of socializing project team members: An integrative approach. International Journal of Project Management, 36(5), 687-700.

Belout, A., \& Gauvreau, C. (2004). Factors influencing project success: The impact of human resource management. International Journal of Project Management, 22(1), 1-11.

Bhoola, V. (2015), “Impact of Project Success Factors in Managing Software Projects in India: An Empirical Analysis". Business Perspectives and Research, Vol. 3 No. 2, pp. 109-125.

Bhoola, V. (2016), Businesses need to pursue value-driven project management. Training $\mathcal{E}$ Development, available at: https:/www.td.org/Publications/Magazines/TD/TDArchive/2016/12/Webex-Businesses-Need-to-Pursue-Value-Driven-ProjectManagement. (accessed 19 May 2017)

Blaskovics, B. (2016), "The impact of project manager on project success -The case of ICT sector". Society and Economy in Central and Eastern Europe, Vol. 38 No. 2, pp. 261-281.

Brancheau, J.C. and Wetherbe, J.C. (1987), "Key issues in information systems management". MIS Quarterly, Vol. 11 No. 1, pp. 23-45

Budhwar, P.S., Varma, A. and Patel, C. (2016), "Convergence-divergence of HRM in the AsiaPacific: Context-specific analysis and future research agenda". Human Resource Management Review, Vol. 26 No. 4, pp. 311-326.

Butler, A.G. (1973), "Project management: a study in organizational conflict". Academy of Management Journal, Vol. 16 No. 1, pp. 84-101.

Carr, S.C., McWha, I., MacLachlan, M. and Furnham, A. (2010), “International-local remuneration differences across six countries: Do they undermine poverty reduction work?" International Journal of Psychology, Vol. 45 No. 5, pp. 321-340.

Carson, C. W. and Kelly, P. (2015). Soft Skills are Vital for Effective Project Controls. Cost Engineering. 57(2), pp 4-11.

Chapman, D. R., Fair, R. C. 1972. Full-information maximum likelihood program: user's guide. Princeton University, Econometric Research Program.

Claudia, L.C. (2010), "Issues of Human Resources, Members of Project Teams in the NGOs: A case study". Annals of the University of Oradea, Economic Science Series, Vol. 19 No. 2.

Coetzer, and Gibbison, G. (2016), "Mediating influence of time management on the relationship between adult attention deficit and the operational effectiveness of project managers". Journal of Management Development, Vol. 35 No. 8, pp. 970-984.

Collins, L. M., Schafer, J. L., \& Kam, C. M. (2001). A comparison of inclusive and restrictive strategies in modern missing data procedures. Psychological methods, 6(4), 330.

Cronbach, L.J. (1990), Essentials of Psychological Testing. Harper \& Row Publishing, New York. 
Cuellar, M. (2010), “Assessing project success: Moving beyond the triple constraint". International Research Workshop on IT Project Management, Paper. 13.

Diegmann, P., Basten, D. and Pankratz, O. (2017), “Influence of communication on client satisfaction in information system projects: A quantitative field study. Project Management Journal, Vol. 48 No. 1, pp. 81-99.

Esteves, J.M. (2014), “An empirical identification and categorisation of training best practices for ERP implementation projects”. Enterprise Information Systems, Vol. 8 No. 6, pp. 665683.

Farndale, E., Scullion, H. and Sparrow, P. (2010), "The role of the corporate HR function in global talent management". Journal of World Business, Vol. 45 No. 2, pp. 161-168.

Florentine, S. (2016), "More than half of IT projects still failing", available at: http://www.cio.com/article/3068502/project-management/more-than-half-of-it-projectsstill-failing.html. (accessed 5 May 2017)

Foss, N.J., Pedersen, T., Fosgaard, M.R., and Stea, D. (2015), “Why complementary HRM practices impact performance: The case of rewards, job design, and work climate in a knowledge-sharing context. Human Resource Management, Vol. 54 No. 6, pp. 955-976.

Frederiksen, A., Lange, F. and Kriechel, B. (2017), "Subjective performance evaluations and employee careers". Journal of Economic Behavior \& Organization, Vol. 134, pp. 408-429.

Gareis, R. (2013), "Changes of organizations by projects". International Journal of Project Management, Vol. 28 No. 4, pp. 314-327.

Graham, J. W., 2009. Missing data analysis: Making it work in the real world. Annual review of psychology, 60, 549-576.

Hair, J. F. J., Black, W. C., Babin, B. J., \& Anderson, R. E. (2010). Multivariate Data Analysis Seventh Edition Prentice Hall.

Hoda, R., \& Murugesan, L. K. (2016). Multi-level agile project management challenges: A selforganizing team perspective. Journal of Systems and Software, 117, 245-257.

Huemann, M. (2010), “Considering Human Resource Management when developing a project-oriented company: Case study of a telecommunication company". International Journal of Project Management, Vol. 28 No. 4, pp. 361-369

Hughes, D. L., Rana, N. P., \& Simintiras, A. C. (2017), “The changing landscape of IS project failure: an examination of the key factors". Journal of Enterprise Information Management, Vol. 30 No. 1, pp. 142-165.

Innotas - "The Project and Portfolio Management landscape, 2015", available at: http://go.innotas.com/SurveyResults-TheProject-and-PortfolioManagement2015Edition_.html. (accessed 13 May 2017)

Jean-Sébastien, V. (2016), “Why projects fail." [White Paper], available at: https://www.linkedin.com/pulse/why-projects-fail-jean-sébastien-vachon (accessed 21 October 2016).

Jick, T.D. (1979), "Mixing qualitative and quantitative methods: Triangulation in action". Administrative Science Quarterly, Vol. 24 No. 4, pp. 602-611. 
Jiang, J.J., Chang, J.Y., Chen, H.G., Wang, E.T. and Klein, G. (2014), “Achieving IT program goals with integrative conflict management". Journal of Management Information Systems, Vol. 31 No. 1, pp. 79-106.

Joslin, R. and Müller, R. (2016), "The impact of project methodologies on project success in different project environments". International Journal of Managing Projects in Business, Vol. 9 No. 2, pp. 364-388.

Katou, A.A., Budhwar, P.S. and Patel, C. (2014), "Content vs. Process in the HRM-Performance relationship: An empirical examination", Human Resources Management, Vol. 53, pp. 527544.

Keegan, A., Huemann, M. and Turner, J.R. (2012), “Beyond the line: exploring the HR responsibilities of line managers, project managers and the HR department in four project-oriented companies in the Netherlands, Austria, the UK and the USA", International Journal of Human Resource Management, Vol. 23 No. 15, pp. 3085-3104.

Keil, M., Lee, H.K. and Deng, T. (2013), “Understanding the most critical skills for managing IT projects: A Delphi study of IT project managers". Information $\mathcal{E}$ Management, Vol. 50 No. 7, pp. 398-414.

Kennedy, D.M., Sommer, S.A. and Nguyen, P.A. (2017), “Optimizing multi-team system behaviors: Insights from modeling team communication". European Journal of Operational Research, Vol. 258 No. 1, pp. 264-278.

Khan, A.S. and Rasheed, F. (2015), "Human resource management practices and project success, a moderating role of Islamic Work Ethics in Pakistani project-based organizations", International Journal of Project Management, Vol. 33 No. 2, pp. 435-445.

Korsakienė, R., Stankevičienè, A., Šimelytė, A. and Talačkienè, M. (2015), “Factors driving turnover and retention of information technology professionals", Journal of Business Economics \& Management, Vol. 16 No. 1, pp. 1-17.

Koulikoff-Souviron, M., \& Harrison, A. (2010). Evolving HR practices in a strategic intra-firm supply chain. Human Resource Management, 49(5), 913-938.

Lee, O.K. and Baby, D.V. (2013), “Managing dynamic risks in global it projects: Agile riskmanagement using the principles of service-oriented architecture". International Journal of Information Technology \& Decision Making, Vol. 12 No. 6, pp. 1121-1150.

Majumdar, S.K. (2013), "R\&D spending and the rewards to human capital in India's IT sector", Vikalpa, Vol. 38 No. 4, pp. 37.

Momeni, K., \& Martinsuo, M. M. (2018). Allocating human resources to projects and services in dynamic project environments. International Journal of Managing Projects in Business, 11(2), 486-506.

Morse, J.M. (2003), "Principles of mixed methods and multimethod research design", In Tashakkori, A. and Teddlie, C. (Eds.), Handbook of mixed methods in social and behavioral research, Sage Publications, Thousand Oaks (Ca., USA), pp. 189-208.

NASSCOM. (2017), "The IT-BPM Sector in India: Strategic Review 2017", available at: http://www.nasscom.in/research-reports. (accessed 12 May 2017) 
Parker, S.K. and Skitmore, M. (2005), "Project management turnover: causes and effects on project performance", International Journal of Project Management, Vol. 23 No. 3, pp. 205214.

Prakash, A. (2016), "E-governance and public service delivery at the grassroots: a study of ICT use in health and nutrition programs in India". Information Technology for Development, Vol. 22 No. 2, pp. 306-319.

Purvanova, R.K. (2013), "The role of feeling known for team member outcomes in project teams". Small Group Research, Vol. 44 No. 3, pp. 298-331.

Remus, U. and Wiener, M. (2010), "A multi-method, holistic strategy for researching critical success factors in IT projects", Information Systems Journal, Vol. 20 No. 1, pp. 25-52.

Rockart, J.F. (1979), “Chief executives define their own data needs". Harvard Business Review, Vol. 57 No. 2, pp. 81-93.

Roebuck, D., Bell, R. L., Raina, R., \& Lee, C. E. C. (2015). The effects of home country, gender, and position on listening behaviors.

Sahoo, B. and Nauriyal, D. (2014), "Determinants of software exports from India". International Economics and Economic Policy, Vol. 11 No. 4, pp. 455-479.

Santos, C., Gonzalez, T., Li, H., Chen, K.Y., Beyer, D., Biligi, S. and Zhang, A. (2013), “HP enterprise services uses optimization for resource planning". Interfaces, Vol. 43 No. 2, pp. 152-169.

Schmidt, R.C. (1997), "Managing Delphi surveys using nonparametric statistical techniques". Decision Sciences, Vol. 28 No. 3, pp. 763-774.

Schmidt, R., Lyytinen, K. Keil, Mark and Cule, P. (2001), “Identifying software project risks: An international Delphi study". Journal of Management Information Systems, Vol. 17 No. 4 , pp. 5-36.

Shenhar, A. J., Dvir, D., Levy, O., \& Maltz, A. C. (2001). Project success: a multidimensional strategic concept. Long Range Planning, 34(6), 699-725.

Standish Group's Chaos Report Outline (2016), available at: http://www.standishgroup.com/outline (accessed 15 April 2017)

Stulgienè, A. and Čiutienè, R. (2012), “HR challenges in transition to project management (project-based organization)". Economics and Management, Vol. 17 No. 3, pp. 1214-1218.

Sutterfield, J.S., Friday-Stroud, S.S. and Shivers-Blackwell, S.L. (2006), “A case study of project and stakeholder management failures: lessons learned". Project Management Quarterly, Vol. 37 No. 5, pp. 26.

Thite, M., Budhwar, P.S. and Wilkinson, A. (2014), “Global HR roles and factors influencing their development: Evidence from emerging Indian IT services multinationals". Human Resource Management, Vol. 53 No. 6, pp. 921-946.

Todorović, M.L., Mitrović, Z. and Bjelica, D. (2013), “Measuring project success in projectoriented organizations". Management, Vol. 68, pp. 41-48.

Tripathi, S.S. (2014), "The role of managers as agents in successful service innovations: Evidence from India", Technology Innovation Management Review, August, pp. 18-26. 
Turner, J. R., \& Müller, R. (2005). The project manager's leadership style as a success factor on projects: a literature review. Project Management Journal, 36, 49-61.

Uzzafer, M. (2013), “A contingency estimation model for software projects". International Journal of Project Management, Vol. 31 No. 7, pp. 981-993.

Van Marrewijk, M., \& Timmers, J. (2003). Human capital management: New possibilities in people management. Journal of Business Ethics, 44(2), 171-184.

Van Dierendonck, D., Lankester, A., Zmyslona, M. and Rothweiler, H. (2016), “Linking HRM practices and institutional setting to collective turnover: An empirical exploration". Administrative Sciences, Vol. 6 No. 4, pp. 18.

Viji, B. (2016), “Enhancement of employee performance through competency mapping in IT sector - An empirical analysis", CLEAR International Journal of Research in Commerce $\mathcal{E}$ Management, Vol. 7 No. 9.

Watson, T. (2008), "Public relations research priorities: a Delphi study". Journal of Communication, Vol. 12 No. 2, pp. 104-123.

Weimann, P., Pollock, M., Scott, E. and Brown, I. (2013), “Enhancing team performance through tool use: How critical technology-related issues influence the performance of virtual project teams". IEEE Transactions on Professional Communication, Vol. 56 No. 4, pp. 332-353.

Zhu, Y.Q. and Kindarto, A. (2016), “A garbage can model of government IT project failures in developing countries: The effects of leadership, decision structure and team competence". Government Information Quarterly, Vol. 33 No. 4, pp. 629-637.

Zhou, E.I., Lu, Z., Li, X., Li, T., Papola, T.S., Pais, J. and Sahu, P.P. (2010). “Remuneration differences in the emerging economies of China and India". International Journal of Psychology, Vol. 45, pp. 360-370.

Zidane, Y. J. T., \& Andersen, B. (2018). The top 10 universal delay factors in construction projects. International Journal of Managing Projects in Business, 11(3), 650-672. 


\section{Appendix 1}

List of HR Activities and Practices (HRAP) items used in the study

\begin{tabular}{|c|c|c|c|}
\hline No & HRAP & No & HR Activities and Practices \\
\hline 1 & Access to internal personnel & 23 & $\begin{array}{l}\text { Just and fair treatment of employees in } \\
\text { workplace }\end{array}$ \\
\hline 2 & Adequate training of project team members & 24 & $\begin{array}{l}\text { Lack of English communications skills of team } \\
\text { members }\end{array}$ \\
\hline 3 & Adequate training to ensure competence & 25 & Listening \\
\hline 4 & $\begin{array}{l}\text { Appointment of project manager / leader for } \\
\text { the project }\end{array}$ & 26 & Making employees feel important \\
\hline 5 & Balancing standardization and customization & 27 & $\begin{array}{l}\text { Performance measurement of individual } \\
\text { members }\end{array}$ \\
\hline 6 & Building a global work culture & 28 & $\begin{array}{l}\text { Periodic formal review of status reports versus } \\
\text { plan }\end{array}$ \\
\hline 7 & $\begin{array}{l}\text { Conflicting and continuous requirement } \\
\text { changes }\end{array}$ & 29 & Personnel turnover at organizational level \\
\hline 8 & $\begin{array}{l}\text { Consultation with employees before assigning } \\
\text { a project }\end{array}$ & 30 & $\begin{array}{l}\text { Proactiveness and helpfulness of HR } \\
\text { department }\end{array}$ \\
\hline 9 & Creating congenial environment for sharing & 31 & $\begin{array}{l}\text { Project leadership and people management } \\
\text { skills }\end{array}$ \\
\hline 10 & Diversification within the project team & 32 & $\begin{array}{l}\text { Promoting a women-friendly work } \\
\text { environment }\end{array}$ \\
\hline 11 & Effectiveness of project team communication & 33 & Promoting formal risk management practices \\
\hline 12 & $\begin{array}{l}\text { Embedding organizational core values in } \\
\text { projects }\end{array}$ & 34 & Promoting innovation \\
\hline 13 & $\begin{array}{l}\text { Extent of team member turnover (members } \\
\text { resigning) }\end{array}$ & 35 & $\begin{array}{l}\text { Promotions \& salaries and individual } \\
\text { performances }\end{array}$ \\
\hline 14 & $\begin{array}{l}\text { Freedom of project manager to select the } \\
\text { project team }\end{array}$ & 36 & $\begin{array}{l}\text { Recognition through rewarding for working } \\
\text { beyond office hours }\end{array}$ \\
\hline 15 & $\begin{array}{l}\text { Freedom of selection of development } \\
\text { platforms \& tools }\end{array}$ & 37 & Relevant experience of team members \\
\hline 16 & $\begin{array}{l}\text { Frequent conflicts between project team } \\
\text { members }\end{array}$ & 38 & $\begin{array}{l}\text { Respecting Indian cultures and ethnic } \\
\text { diversity }\end{array}$ \\
\hline 17 & Frequent shuffling of project team members & 39 & $\begin{array}{l}\text { Restrictions on women members on travel \& } \\
\text { stay outside }\end{array}$ \\
\hline 18 & $\begin{array}{l}\text { Holding individuals accountable for tasks } \\
\text { assigned }\end{array}$ & 40 & $\begin{array}{l}\text { Restrictions on working hours for women } \\
\text { members }\end{array}$ \\
\hline 19 & Individual needs and values & 41 & Staff motivation \\
\hline 20 & Ineffectiveness of project manager & 42 & Strict enforcement of attendance \\
\hline 21 & Inexperience of project leader & 43 & $\begin{array}{l}\text { Taking of unnecessary safety risks to perform } \\
\text { job }\end{array}$ \\
\hline 22 & Job-matching to enhance performance & 44 & Training of project leaders \\
\hline
\end{tabular}

Copyright: (C 2018 Bhoola \& Giangreco. This is an open-access article distributed under the terms of the Creative Commons Attribution-NonCommercial 3.0 Australia License, which 
permits non-commercial use, distribution, and reproduction in any medium, provided the original author and AJIS are credited.

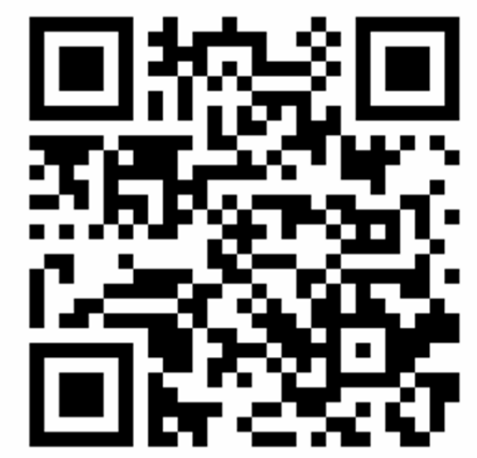

